\title{
Grupos solidarios de microcrédito y redes sociales: sus implicancias en la generación de capital social en barrios del Gran Buenos Aires
}

\author{
Pablo Forni ${ }^{1}$, IDICSO, Universidad del Salvador, Argentina \\ Mariana Nardone, IDICSO, Universidad del Salvador, Argentina
}

\begin{abstract}
Resumen
El capital social es un recurso que surge de las relaciones sociales, gracias a las cuales los actores se aseguran beneficios en virtud de la pertenencia a redes $u$ otras estructuras sociales. Por tanto, diferencias en la estructura de las redes resulta en distintos tipos de capital social. Aquí se analizan los grupos solidarios de microcrédito en Cuartel V, Moreno (Gran Buenos Aires, Argentina), centrándonos en su capacidad de generar distintos tipos de capital social a partir de la red social que constituyen. Los objetivos planteados consisten en analizar a través de qué procesos de asociación u organización comunitaria se genera capital social, para comprender si su construcción es fomentada por el establecimiento de vínculos estrechos o si más bien surge de la capacidad de los actores para establecer diferentes relaciones fuera de su entorno. Se analizan las relaciones que se establecen entre distintos grupos solidarios, una ONG de Desarrollo y una organización comunitaria, y se indaga sobre la fuerza y centralidad en la red, considerando individuos, grupos y organizaciones. La estrategia metodológica es cualitativa basada en entrevistas y grupos focales. Asimismo se combinan aportes conceptuales del capital social y el análisis de redes. Entre los hallazgos puede destacarse que la existencia de grupos de microcrédito en Cuartel $V$ es posible gracias al capital social de una arraigada organización comunitaria local. Asimismo, los grupos solidarios se constituyen a partir de redes inter-personales preexistentes densas de familiares $y / 0$ vecinos que generan capital social de unión y/o vinculación y que la ONG impulsa el desarrollo de estos vínculos al tiempo que se genera capital social de puente entre estos actores.
\end{abstract}

Palabras clave: pobreza - organizaciones comunitarias - capital social - redes microcrédito

\begin{abstract}
Social Capital is a resource resulting from social relations, by which actors ensure themselves benefits thanks to their belonging to networks or other social structures. Thus, differences in network structure results in different types of social capital. Here, we analyze micro credit solidarity groups in Cuartel V, Moreno (Greater Buenos Aires, Argentina), paying attention to its capacity of generating different types of social capital from the social network its constitute. The objectives are to analyze through which associative or organizational processes social capital is created, in order to asses if it is propped by the establishment of close ties or rather by the ability of actors to establish different relationships outside their environment. The relationships established between solidarity groups, the Fundación Pro Vivienda Social and a community organizations; investigating about intensity and centrality in the network, considering individuals, groups and organizations. The methodological strategy is qualitative as based on interviews
\end{abstract}

\footnotetext{
${ }^{1}$ forni@mail.retina.ar; mariananardone@yahoo.com.ar
} 
REDES- Revista hispana para el análisis de redes sociales

Vol.9, \#5, Diciembre 2005.

http://revista-redes.rediris.es

and focus groups and the theoretical framework combines insights from social capital and social network analysis. Among the findings we can highlight that the very existence of micro credit groups in Cuartel $\mathrm{V}$ is made possible by social capital and a well established local community organization. Also, solidarity groups constitute themselves from pre-existent dense inter personal networks of family members and/or neighbors generating bonding and/or linking social capital and that the Fundación propel the development of such relationships while generating bridging social capital between these actors.

Key words: poverty - community organizations - social capital - networks microcredit

\section{I ntroducción}

El capital social es un recurso que surge de las relaciones sociales, gracias a las cuales los actores se aseguran los beneficios en virtud de la pertenencia a redes $u$ otras estructuras sociales. Utilizando la definición de Robert Putnam, puede decirse que el capital social consiste en "...rasgos de organizaciones sociales, como redes, normas y confianza, que facilitan la acción y la cooperación en beneficio mutuo" (Putnam, 1993: 35).

Los objetivos planteados consisten en analizar a través de qué procesos de asociación u organización comunitarias se genera capital social en contextos de exclusión en el Gran Buenos Aires (Argentina), para comprender si la construcción de capital social es fomentada por el establecimiento de vínculos estrechos ("la cercanía de las redes sociales"), o si más bien surge de la capacidad de los actores para establecer diferentes relaciones fuera de su ámbito más inmediato ("las conexiones puente").

Se analizan los grupos solidarios de microcrédito para la mejora de la vivienda promovidos por la Fundación Pro Vivienda Social -en adelante FPVS- (Cuartel V, Moreno, Pcia. de Buenos Aires, Argentina). Se indaga sobre cómo, a través de los grupos solidarios de microcrédito, se promueve el desarrollo de redes y concomitantemente diferentes tipos de capital social en ámbitos de exclusión, analizando estas relaciones durante la experiencia del Programa de Mejoramiento Habitacional2 de FPVS en el período 2004-2005. El análisis de redes abordado en el presente trabajo es de carácter organizacional, en tanto consideramos relevantes los vínculos que se establecen entre los diversos componentes de la red tanto a nivel grupal, como organizacional. El argumento desde el que se parte consiste en que las características de las redes implicarían distintas formas de capital social.

\footnotetext{
${ }^{2}$ Programa de Mejoramiento Habitacional de FPVS, disponible en: http://fpvs.org/programas/mh/queproponemos. php
} 
REDES- Revista hispana para el análisis de redes sociales

Vol.9,\#5, Diciembre 2005.

http://revista-redes.rediris.es

\section{Estrategia metodológica}

La estrategia metodológica es cualitativa. Dado que nuestro principal objetivo es analizar a partir de qué procesos es posible obtener resultados en términos de capital social, se presta atención tanto a la Fundación y los grupos solidarios, como así también a las relaciones que establecen una y otros en la comunidad analizada.

La unidad de recolección fueron principalmente miembros de los grupos solidarios así como directivos y personal de la Fundación Pro Vivienda Social; asimismo incluimos en nuestras entrevistas a un informante clave de una organización comunitaria, la Mutual El Colmenar, pues a medida que avanzábamos en el trabajo de campo notamos que la misma constituye un importante componente de la red que se forma alrededor del Programa de Mejoramiento Habitacional. Se realizaron un total de 17 entrevistas en profundidad.

Durante el año 2005 existen cincuenta grupos solidarios de microcrédito en Cuartel $V$, de los cuales se entrevistó a miembros de diez grupos. Se trató de una muestra intencional cuyo criterio de selección consistió, por un lado, en tomar aquellos en los que la garantía solidaria se cumplía y aquellos otros en los que no fuera así, y asimismo se tomaron grupos que difieren entre sí en el tipo de vínculos que hay a su interior (familiares, vecinales y mixtos -familiares/laborales y familiares/vecinales). Con respecto al número final de grupos seleccionados, esta consideración estuvo ligada al concepto de saturación, en tanto nuevas entrevistas no aportan información novedosa. Para la selección y acceso a los entrevistados se contó con la colaboración del personal de la Fundación.

Se utilizaron las siguientes técnicas de recolección: a) observación no participante en los grupos, la Fundación y las reuniones previstas por ésta, la cual nos permitió recabar aquellos datos que no son perceptibles a través de otras técnicas; b) entrevistas en profundidad semi estructuradas; la utilización de un esquema nos facilitó la tarea de abordar los objetivos de la investigación, indagando acerca de la organización de la Fundación, la metodología del microcrédito y la garantía solidaria, la constitución de redes inter-organizacionales, los vínculos entre los miembros y entre éstos y la Fundación, la frecuencia y fuerza de los vínculos entre los miembros del grupo con la Fundación y los vínculos con otras organizaciones comunitarias; c) asimismo se empleó la técnica del grupo focal con miembros de distintos grupos solidarios; este método fue de utilidad en el momento del cierre del estudio, para interpretar hallazgos que fueron surgiendo a lo largo de las entrevistas. Además el objetivo de su realización fue saber qué es expresado en un 
REDES- Revista hispana para el análisis de redes sociales

Vol.9,\#5, Diciembre 2005.

http://revista-redes.rediris.es

contexto grupal, diferenciado del individual y confidencial que obtuvimos en la gran mayoría de las entrevistas.

\section{La articulación de redes sociales y los tipos de capital social}

Si bien la preocupación por las fuentes de la solidaridad social puede rastrearse hasta los propios orígenes de las ciencias sociales, en los últimos años el concepto de capital social ha generado un importante debate académico. Aquí presentamos brevemente algunas definiciones sistemáticas y contemporáneas de capital social, como aquélla que encontramos en autores tales como Coleman, Putnam, Burt y Granovetter.

J. Coleman define el capital social como “...una diversidad de entidades con dos elementos en común: todas consisten en algún aspecto de estructuras sociales y facilitan cierta acción de los actores (ya se trate de personas o actores corporativos) dentro de la estructura" (Coleman, 1990: 302). Es decir, se trata de un recurso de la estructura en la cual los individuos están insertos, que ayuda a lograr objetivos personales y que en caso de ausencia de este capital no podrían alcanzarse. Coleman enfatiza en el grado de cercanía (closure) de las relaciones entre los individuos que facilitará la acción colectiva, donde los beneficiarios del capital social serán todos aquellos que formen parte de esa estructura social. Mientras Coleman pone el énfasis en la densidad de las redes como condición para el surgimiento del capital social, otro autor, M. Granovetter, hacia 1974 expresó una idea diferente a través del concepto de "fortaleza de los vínculos débiles" para referirse por ello a la capacidad de las influencias indirectas exteriores al círculo inmediato de la familia y los amigos más cercanos para servir como un sistema informal de referencia de empleos. Él señala que “...aquellos con quienes estamos débilmente vinculados son más propensos a moverse en círculos distintos al propio y, por tanto, tendrán acceso a una información diferente a la que nosotros recibimos" (Granovetter, 1973).

R. Burt va a nutrirse de esta fuente de inspiración para destacar casi veinte años más tarde una concepción semejante en la cual, según su opinión, es la relativa ausencia de vínculos (que da en llamar "huecos estructurales") aquello que facilita la movilidad individual. Esto es así en tanto que, como explica el autor, las redes densas tienden a transmitir información redundante, mientras que los vínculos más débiles pueden ser fuentes de nuevos conocimientos y recursos (Portes, 1999). 
REDES- Revista hispana para el análisis de redes sociales

Vol.9,\#5, Diciembre 2005.

http://revista-redes.rediris.es

De la literatura presentada hasta aquí surge la centralidad de la conformación de redes sociales, aunque sin estar exenta de controversias a su interior. De acuerdo al argumento denominado "la cercanía de las redes sociales" perteneciente a J. Coleman, a medida que el grado de interdependencia entre los individuos aumenta (a raíz del establecimiento de relaciones de obligaciones y expectativas recíprocas) la densidad de las redes se incrementa generando altos niveles de cohesión intragrupo, condición sine qua non para la creación de capital social. Esto es así porque sólo a partir la existencia de relaciones lo suficientemente estrechas es posible el surgimiento de un sistema de normas y sanciones, el que influirá positivamente en el desarrollo y la continuidad de relaciones basadas en la confianza y reciprocidad.

R. Burt en cambio enfatiza el papel de "agujeros estructurales" (structural holes) y "las conexiones puente". Desecha la importancia de la densidad de las redes y se enfoca en la calidad de las mismas, midiéndose ésta en función de la posibilidad de acceso a información referente a entornos lejanos e inaccesibles al individuo por sí solo. Burt concuerda con Coleman en que los individuos mejor conectados son quienes disfrutan de mayores beneficios. El desacuerdo aparece a la hora de definir qué significa estar "mejor conectado" (Burt, 2000). El autor, haciendo una observación sobre la estructura social de mercado, concluye que aquellos individuos cuyas relaciones logran superar los agujeros estructurales son quienes cuentan con una ventaja competitiva respecto del resto; son quienes cuentan con un grado mayor de capital social, en tanto sus redes de relaciones le otorgan acceso a mayor información, la que le brinda posibilidades de acción más amplias. Puede señalarse entonces que para Burt, la construcción de capital social no parte del establecimiento de vínculos estrechos, sino de la capacidad de los actores para establecer diferentes relaciones fuera de su grupo de pertenencia (Forni, Siles \& Barreiro, 2004).

De lo referido hasta aquí puede decirse que el capital social es fundamentalmente relacional y sólo puede generarse a partir de vínculos o relaciones entre agentes (sean estos individuales o colectivos). La definición desde la que partimos para hablar de red social es la siguiente: "Se trata de un conjunto de actores (o puntos, nodos o agentes) entre los que existen vínculos (o relaciones). Las redes pueden tener muchos o pocos actores y una o más clases de relaciones entre pares de actores" (Hanneman, 2000: 3). 
REDES- Revista hispana para el análisis de redes sociales

Vol.9, \#5, Diciembre 2005.

http://revista-redes.rediris.es

Las redes también sirven para conectar a diferentes segmentos de la sociedad (Robison, Siles \& Schmid, 2003). Así como las relaciones que se establecen entre familiares, amigos o compañeros de trabajo generan frecuentemente vínculos informales que a su vez constituyen pequeñas inversiones en capital social, también nos encontramos con "formas más elevadas de participación social": las asociaciones comunitarias. Pero tanto una como otra forma son muy importantes en el sostenimiento de las redes sociales (Putnam, 2000).

El análisis de las relaciones inter-organizacionales requiere entonces de la aplicación de las formulaciones hechas por Granovetter acerca de la importancia de los vínculos débiles. Al analizar el capital social a nivel comunitario en zonas de exclusión social, se parte de la base que la segmentación y el aislamiento son rasgos característicos de la pobreza. Si se concluye que el proceso de segmentación lleva implícita la homogeneidad social en los contactos de las personas pobres, sus consecuencias se traducen en pocas oportunidades de superar su situación actual. Es por ello que en el presente trabajo creemos que es importante tomar en cuenta los vínculos que las personas y las organizaciones de la comunidad establecen tanto dentro como fuera de ésta, para conocer los distintos tipos de capital social que se generan (Forni, Siles \& Barreiro, 2004), a saber:

- Niveles intensivos de capital social son aquellos que existen entre los miembros de una familia o amigos cercanos; son llamados bonding social capital o de unión. Se basan en el afecto y la preocupación por el otro. Existen en relaciones socialmente estrechas.

- Otro tipo de capital social que existe en relaciones medianamente estrechas es el denominado linking social capital o de vinculación. El mismo se basa en los sentimientos de compañerismo y buena voluntad recíproca que puede existir entre personas de la misma condición e iguales recursos.

- Niveles de menor intensidad de capital social son denominadas bridging social capital o de aproximación. Este nivel se basa en los sentimientos de respeto o conciencia de la existencia del otro que puede haber entre personas que mantienen una relación asimétrica de poder e influencia. Existe en las relaciones asimétricas entre personas que tienen pocos puntos de coincidencia y diferencias importantes en cuanto a los recursos que poseen. 
REDES- Revista hispana para el análisis de redes sociales

Vol.9,\#5, Diciembre 2005.

http://revista-redes.rediris.es

\section{Los grupos solidarios de microcrédito, la Fundación Pro Vivienda Social y la Mutual El Colmenar}

Existe una amplia trama de instituciones del tercer sector, destinadas a colaborar en la satisfacción de las demandas que surgen de los sectores más necesitados de la sociedad, erigiéndose cada vez más con un rol protagónico dentro del campo social y especialmente en la resolución del problema habitacional. Surgen así propuestas desde la comunidad y desde las Organizaciones no Gubernamentales (ONGs) que plantean alternativas de mejoramiento.

La Fundación Pro Vivienda Social fue creada en 1992 y tiene como objetivo contribuir a la solución del problema de la pobreza, concentrando su accionar en el mejoramiento de la vivienda y de las condiciones de vida de los sectores más necesitados, buscando impulsar su protagonismo en la solución de sus conflictos. Para lograrlo, actúa asociativamente con organizaciones comunitarias locales. La zona de acción de la Fundación es el noroeste del segundo cordón del Área Metropolitana de Buenos Aires. El foco principal de las operaciones de microcrédito llevadas a cabo por la organización es el partido de Moreno, donde se encuentra uno de los índices más elevados de hogares con necesidades básicas insatisfechas entre los 24 municipios del Gran Buenos Aires. Dentro del partido, la localidad de Cuartel $V$ es aquélla donde se concentra la población de menores recursos (fuente: www.moreno.gov.ar). La situación habitacional es muy problemática en esta zona. La Fundación colabora en la solución habitacional de Cuartel V, reduciendo los tiempos que implican mejorar una vivienda, gracias al otorgamiento de microcréditos. Específicamente se entiende por éstos a aquellos pequeños empréstitos otorgados a quienes son demasiado pobres para acceder o calificar a préstamos bancarios (Cheston \& Reed, 1999).

La Fundación otorga créditos que se respaldan con una garantía solidaria. La misma permite a personas sin documentación de ingresos y vivienda, ser sujetos de crédito, facilitando las condiciones de acceso al financiamiento de esta comunidad y acompañando el proceso por el cual la familia va mejorando su vivienda. Al conformarse los grupos se contribuye a bajar el riesgo crediticio y por lo tanto la tasa de interés. Todos los miembros actúan como garantes co-responsables ante la devolución del crédito grupal, por lo tanto, si bien pueden existir ciertas diferencias en el monto que a cada uno de los integrantes del grupo se le otorga, desde la Fundación se trata que éste sea relativamente homogéneo, para que en caso de tener que recurrir a la garantía solidaria, la misma se pueda cumplir con mayor facilidad. Los integrantes se eligen entre sí sin intervención de la Fundación. Los 
REDES- Revista hispana para el análisis de redes sociales

Vol.9,\#5, Diciembre 2005.

http://revista-redes.rediris.es

grupos deben estar conformados por una cantidad de entre 3 y 5 personas, que difieren en el tipo de vínculos que existe entre ellos: son generalmente familiares, vecinales o mixtos. Asimismo, al menos uno de los integrantes debe ser, como condición, ex cliente de la Fundación.

FPVS está organizada del siguiente modo: por una parte se encuentra la Sede Central, encargada de establecer los lineamientos estratégicos de acuerdo a los avances del Programa, así como también se ocupa de la gestión de financiamiento. Por otra parte hallamos la Subsede, localizada en el mismo barrio donde la Fundación actúa con los grupos solidarios.

Por otro lado encontramos un vínculo entre la Fundación y la Mutual El Colmenar, dada la trayectoria que tienen trabajando juntas no sólo desde los primeros acercamientos de la Fundación en el barrio, momento en que fue apoyada por la Mutual, sino que también las liga un vínculo de colaboración y asesoramiento en la actualidad.

\section{El desarrollo del Programa de Mejoramiento Habitacional}

\section{1 Fuerza y centralidad en la red}

Comenzando por lo más micro, podemos ver cómo las redes al interior de una familia, entre vecinos o compañeros de trabajo conforman un grupo. Cada uno de los grupos solidarios de microcrédito constituye una micro-red y la totalidad de los mismos forman un componente de la red más amplia aquí considerada. Asumimos que los actores que comparten las mismas posiciones son similares en sus modelos de relación.

Este componente se encuentra vinculado a la Fundación Pro Vivienda Social, y asimismo por su ubicación geográfica en Cuartel $V$ se vincula con un actor de suma importancia: la Mutual El Colmenar. Es decir que las personas aquí analizadas se encuentran enlazadas a redes, que están vinculadas a redes que a su vez están también enlazadas a redes. Así este conjunto de datos contiene información sobre por lo menos dos tipos de entidades sociales: personas y organizaciones.

Aquí desarrollamos un esquema (Figura 1) para identificar los diferentes niveles de análisis - grupal y organizacional-. La categoría de análisis utilizada es la de fuerza que es función de la frecuencia de la interacción así como de la intensidad de la misma. La intensidad alude al grado de implicación emocional asociado con la relación (Hanneman, 2000). Para denotar la fuerza de las relaciones, se ha indagado sobre la frecuencia de los contactos y sobre la intensidad de los vínculos con cada actor en la red. 
REDES- Revista hispana para el análisis de redes sociales

Vol.9,\#5, Diciembre 2005.

http://revista-redes.rediris.es

Figura 1. Redes: Fuerza y centralidad

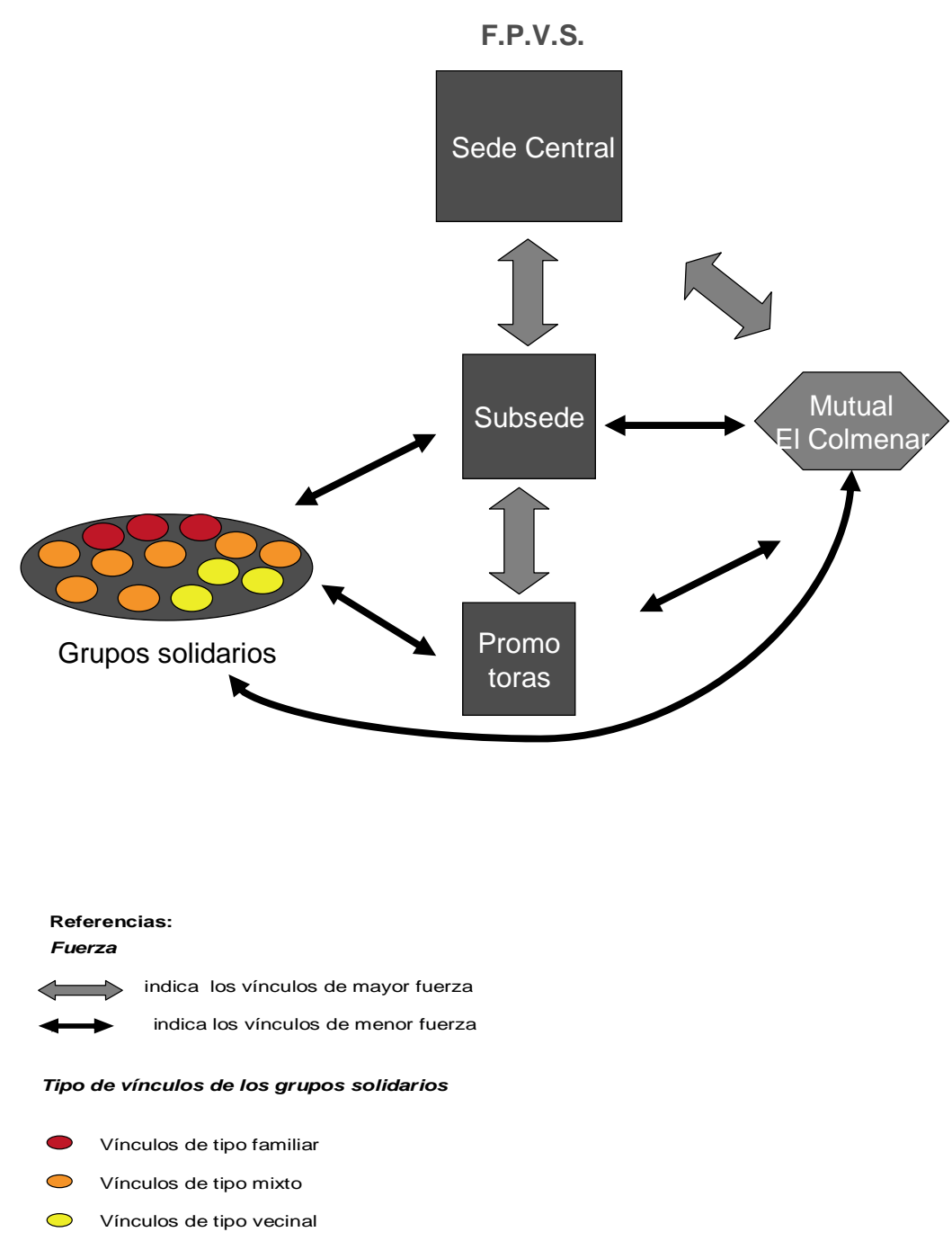

Podemos decir que si bien la Sede Central posee los mayores recursos, es en realidad la Subsede quien tiene el mayor grado de centralidad, pues tiene vínculos con todos los actores en la red (Hanneman, 2000).

Si nos referimos al número y la longitud de los caminos que poseen los actores entre sí, vemos de nuevo que la Subsede tiene más de un camino hacia otros actores, y por ende, puede ser más influyente sobre ellos. "Los actores que tienen caminos cortos a muchos otros actores pueden ser figuras influyentes o centrales. 
REDES- Revista hispana para el análisis de redes sociales

Vol.9,\#5, Diciembre 2005.

http://revista-redes.rediris.es

Entonces, el número y la longitud de los caminos en una red son muy importantes para entender tanto las limitaciones individuales como las oportunidades, y para entender el comportamiento y potenciales de la red en su totalidad" (Hanneman, 2000: 16). Como puede observarse en la Figura 1, la Subsede es crucial para el Programa de Mejoramiento Habitacional de la Fundación y para la generación de capital social, dado que se encuentra vinculada con cada uno de los otros actores, se encuentra más cercana a todos ellos y está situada entre cada par de actores, constituyéndose en la articuladora del Programa en Cuartel V.

A continuación haremos un análisis más descriptivo, indagando sobre el tipo de relaciones que establecen los grupos y las organizaciones comunitarias entre sí y las relaciones que establecen con organizaciones o actores sociales dentro y fuera de su comunidad.

\subsection{Los vínculos informales. Grupos.}

Comencemos por analizar las micro-redes que se generan al interior de los grupos de microcrédito impulsados por la Fundación. Los grupos analizados comparten, en su mayoría, una ubicación geográfica y una situación económica, social y cultural similares.

La búsqueda de respuestas a las necesidades ligadas a la vivienda ha impulsado el surgimiento de una gran cantidad de grupos y experiencias diversas, como ser, según se advierte a partir de lo referido por los entrevistados, los "círculos de dinero" pre-existentes al accionar de la Fundación en la zona. Este tipo de experiencia genera vínculos entre los vecinos, familiares o compañeros de trabajo, y además es una manera de conocer el comportamiento del otro a la hora de cumplir.

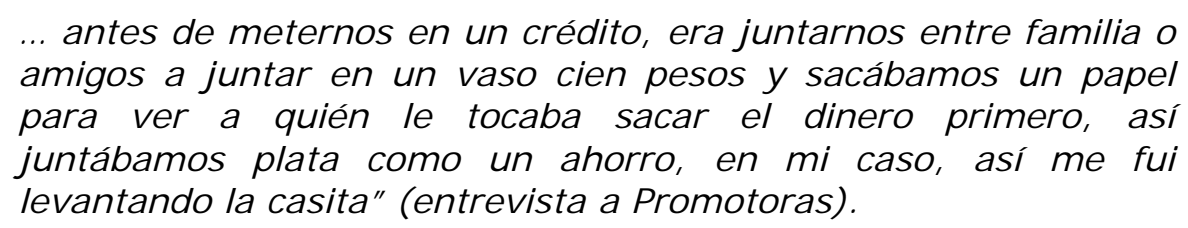

Podría decirse que las redes que la propia gente tiene de vecindad, de familiaridad o de relación de trabajo están conformadas y son previas a la llegada de la Fundación, pero sin embargo el microcrédito a través de la garantía solidaria estaría "formalizando" a las mismas. Más allá de esto, las redes al interior de los grupos no actúan simplemente como satisfactor de las necesidades, sino también como posibilidad para generar mayores relaciones, apoyos y pertenencias. 
REDES- Revista hispana para el análisis de redes sociales

Vol.9, \#5, Diciembre 2005.

http://revista-redes.rediris.es

Se armó como una familia, yo no la voy a defraudar a ella, yo tengo mi responsabilidad de pagar" (Entrevista al grupo Bambi. Tipo: vecinal).

- ¿Qué se gana y qué se pierde formando un grupo?

- Por ahí el compañerismo, el apoyo, en el estar en un grupo sentís más la contención; el hecho de que si por ahí te va mal, todo eso, y bueno, el grupo siempre te apoya." (Entrevista a grupo El Parque. Tipo: vecinal).

Las relaciones estrechas encuentran su expresión más clara en el ámbito de la familia, la cual constituye una red de relaciones cercanas entre un conjunto de personas; los grupos constituidos por familiares se recluyen en lo privado, en lo más próximo y conocido. Las redes que se constituyen en los grupos de tipo familiar se identifican primero en tanto red simple de organización, donde hay cierta división de roles asociados a la organización del hogar. Aquí intervienen desde valores hasta cuestiones de género y generacionales.

... son palabras sagradas, mi papá, mi hermano y mi tío son palabras sagradas, es decir confiamos uno al otro, yo sé que si los necesito, los tengo, entonces bueno, ésa es la clave" (Entrevista a grupo Mayo. Tipo: familiar).

Como en el caso de mi hijo, que hoy sacamos, no sé si pasó dos días, él ya estaba haciendo la perforación que es la base principal del agua. Y para la perforación completa no le alcanzó el dinero que sacó, así que la pagué yo como mamá. Yo le dije: 'Yo te presto de la plata que saqué'... (Grupo Focal).

Luego existe otra red constituida a nivel local, que trasciende el marco de lo estrictamente familiar; son las redes al interior de los grupos vecinales. Aquí las relaciones son medianamente estrechas, y pueden incluir una gama de acciones que van desde la ayuda desinteresada hasta el intercambio de bienes y servicios.

Por último nos encontramos con las redes de los grupos mixtos. Aquí la red se sustenta en relaciones sociales en sentido amplio, e incluye familiares, compañeros de trabajo, vecinos.

Una señora formó un grupo hace siete años (...) Y yo comentando con ella que quería sacar un préstamo, y le decía lo difícil que era, entonces ella me dice: 'Yo voy a ver, usted me gusta para ponerla en el grupo, porque la veo muy responsable y tiene que ser gente responsable, que pague...' y yo le dije: 'No, no, Juanita, yo soy responsable' (...) Eran vecinos en ese grupo, quedé sola, y pongo a una amiga mía, que es muy responsable, que yo la conozco, después integramos a la hermana de mi amiga" (Entrevista a grupo Los Pininos. Tipo: mixtofamiliar/vecinal). 
REDES- Revista hispana para el análisis de redes sociales

Vol.9, \#5, Diciembre 2005.

http://revista-redes.rediris.es

Tratamos de ayudarnos, no es que estamos pendientes de lo que le va a pasar al otro, pero los problemas del círculo se saben..." (Grupo Focal).

Este tipo de amalgamiento no está exento de conflictos a su interior, y los vínculos familiares, morales y vínculos personales, no siempre implican mayor responsabilidad entre los miembros.

Yo con algunos parientes me llevo espectacular, con otros soy un desastre, no armaría un grupo ni auque me pagaran ellos la cuota" (Grupo Focal).

Incluso puede decirse que en algunos grupos la experiencia a partir del microcrédito terminó generando cierta desconfianza entre los integrantes del grupo.

...hubo un problema con un integrante del grupo con el asunto de la plata, y entonces ya es como que todo el grupo se desconfió uno al otro, y ya cada uno va a pagar lo suyo (...) Sería mi hermana, digamos ¿no?, porque sería la esposa de mi cuñado, la macana que se mandaron ellos. Pero obvio que ese grupo ya fue, porque los otros chicos tampoco ya no quieren hacer grupo con ella (...) ya la confianza ya no es la misma." (Entrevista a grupo Los Patacones. Tipo: mixto-familiar/vecinal).

En general, las prácticas de intercambio en los grupos de microcrédito requieren tanto implícita como explícitamente una devolución. Es decir que hay una exigencia de cumplimiento de los pagos, dentro de un período determinado de tiempo. Por lo tanto estas redes, del tipo que sean (familiar, vecinal o mixto) toman características de un intercambio definitivamente regulado.

Es una unión que tenemos nosotros, por ejemplo si mi suegra no puede trabajar, yo ya sé que tengo que poner un poco más, lo mismo con la otra parte y ponemos un poco más los dos" (Entrevista a grupo Caacupe. Tipo: mixto -familiar/laboral).

...yo le dije: 'Yo lo único que quiero, bueno, si tenemos que pagar nosotros yo lo que quiero es que si me tienen que dar la plata a mí que me den la plata un día antes'..." (Entrevista a grupo Macarena. Tipo: mixto-familiar/vecinal).

Y sobre todo yo soy muy franca, yo te digo, la amistad está todo bien, pero en la hora de pagar yo soy muy realista, a mí me gusta decirle francamente 'mirá, nosotros somos amigos pero en la hora que tenemos que pagar, la plata tiene que estar'... (Grupo Focal). 
REDES- Revista hispana para el análisis de redes sociales

Vol.9, \#5, Diciembre 2005.

http://revista-redes.rediris.es

\subsection{Grupos solidarios y organizaciones comunitarias: la presencia de la Mutual El Colmenar}

Hasta aquí consideramos las relaciones que se establecen entre familiares, vecinos o compañeros de trabajo, que generan frecuentemente vínculos informales, que a su vez constituyen pequeñas inversiones en capital social. Pero asimismo las redes sirven para conectar diferentes segmentos de la sociedad. En el análisis es importante tomar en cuenta los vínculos que las personas y las organizaciones de la comunidad establecen tanto dentro como fuera de ésta, para conocer los distintos tipos de capital social que se generan (Forni, Siles \& Barreiro, 2004). Aquí nos encontramos con formas de participación social más elevadas: las organizaciones comunitarias. Particularmente la Mutual El Colmenar tuvo y tiene un peso importante dentro de la comunidad.

...las organizaciones hablan de la Mutual como un referente de organización social y de un modelo de organización comunitaria y de una manera de hacer las cosas que tiene que ver con la asociación y no clientelismo" (Entrevista a informante clave de Mutual El Colmenar).

El colectivo, bueno, ayudaba, colaboraba con la gente, porque si un chico no tenía para el boleto, o uno le pedía '¿Me llevás?', a mí me pasó una vuelta, te llevaba. Otro colectivo no te lleva ni a palos, si no tenés una moneda, 'no te subas porque te bajo'; en ese sentido. Después cuando eran los velatorios, yo me acuerdo que el colectivo se prestaba a llevar a la gente, o sea que otro colectivo no te lo va a hacer" (Entrevista a grupo Los Patacones).

El Colmenar es una mutual que tiene como actividad principal el brindar servicios a sus socios, fundamentalmente el transporte de pasajeros. Sus orígenes se remontan aproximadamente hace 15 años atrás, y es resultado de las acciones de un grupo reducido de militantes comunitarios, pobladores de la zona, que emprendieron distintas iniciativas para solucionar los problemas del área en los campos de educación, vivienda, salud, seguridad, comunicaciones, provisión de alimentos, etc. (Forni, 2002b).

Desde un comienzo el proyecto de los colectivos, su actividad principal, tuvo un gran éxito, ya que llegaba a áreas que no cubría la empresa de transporte público de pasajeros (La Perlita, línea 501); además contaba con tarifas hasta un 50\% menores a las de dicha empresa. Pero sus acciones a favor de la comunidad de Cuartel V nunca estuvieron exentas de dificultades. Así como al inicio de su servicio de transporte, hacia 1990, encontró obstáculos frente a la "guerra de precios" impartida por La Perlita y su incorporación de nuevos recorridos en la localidad e agregación de más unidades en el recorrido que compartía con la Mutual (Forni, 
REDES- Revista hispana para el análisis de redes sociales

Vol.9,\#5, Diciembre 2005.

http://revista-redes.rediris.es

2002b), esta situación vuelve a repetirse en la actualidad, desatando un nuevo conflicto entre las dos líneas de colectivos, generando esta vez un freno en el servicio ofrecido por la Mutual.

Y con el Colmenar vos subís al colectivo y subís al colectivo de un amigo. Se siente mucho la ausencia de ellos" (Grupo Focal).

\subsection{Mutual El Colmenar y FPVS}

Para el establecimiento de relaciones inter-organizacionales existen factores que colaboran en la cooperación entre las organizaciones, que puede ir desde la escasez de recursos o malestar en el funcionamiento, hasta la existencia de valores que subrayan la cooperación como algo positivo, y fuerzas extra-organizacionales que demandan cooperación. En nuestro caso la unidad entre El Colmenar y la Fundación es la unión inter-organizacional más profunda que encontramos en el caso estudiado, dado que los une una relación de trabajo de muchos años. La misma se basa en la necesidad de legitimación en el área para que fuera posible la instalación de una línea de crédito para el mejoramiento de la vivienda. El lanzamiento del Programa de Mejoramiento Habitacional se hizo en asociación con la Mutual, fortaleciendo y legitimando a la Fundación en la zona, como un paso necesario para su supervivencia y éxito en la prosecución de sus objetivos (Forni, 2002b).

El Colmenar ayudó de muchas maneras, primero a través de sus ómnibus y su tema de los stickers para que la gente se enterara; después haciendo promoción de manera directa a través de las personas que se ocupan de las ventas. Con toda esa actividad ellos colaboraron en darle visibilidad a todo el tema de los créditos, de hecho algunos de nuestros clientes hablan de los créditos de El Colmenar, hay una especie de mimetización entre la Fundación y la Mutual, pero como colaboramos juntas no tenemos problemas de cartel" (Entrevista a Dir. Ejecutivo de FPVS).

\subsection{Las Relaciones entre la Mutual y la Fundación}

Las relaciones entre organizaciones no se consolidan de manera inmediata sino que constituyen procesos graduales (Forni, 2002a). En la primera etapa de conformación de la red, estadio en que se constituyen espacios de comunicación e intercambio de información, temores y experiencias, el proceso de surgimiento de las relaciones inter-organizacionales estuvo marcado por un reconocimiento mutuo. El Colmenar desde su gestación trabajó llevando a cabo algunos emprendimientos que otorgaban materiales para la construcción (en colaboración con otras organizaciones). 
REDES- Revista hispana para el análisis de redes sociales

Vol.9, \#5, Diciembre 2005.

http://revista-redes.rediris.es

Cuando en 1995 la Fundación Pro Vivienda Social decidió lanzar el Programa de Mejoramiento Habitacional, El Colmenar para ese entonces ya trataba con gran cantidad de gente que quería obtener créditos. Entonces se tomó la decisión de hacer una alianza y se definió que el servicio se diera en Cuartel V.

Distintos motivos impulsaron la constitución de espacios de encuentro entre la Fundación y el Colmenar: la necesidad de la gente que El Colmenar tenía registrada por su experiencia previa; el conocimiento de los miembros de la Fundación y la posibilidad que tenía la Mutual de contactarse con la comunidad, así como el trabajo en conjunto de años. De esta manera se fue gestando la confianza entre ambas. Pero esta relación no estuvo exenta de dificultades:

Después las dificultades se vieron, pero no fueron realmente importantes. Tuvieron que ver con el amalgamar dos tipos de cultura organizacional distintas, la Mutual tiene una cultura más de desarrollo comunitario, más de organización de base, menos organizada, poniendo menos el eje en los procedimientos; y bueno, la Fundación venía con todo un bagaje de una organización más estructurada, con procedimientos bien detallados, con medición de tiempos y resultados. Ésa fue la dificultad... no lo vería como una dificultad quizá fue más un desafío...el amalgamar" (Entrevista a informante clave de Mutual El Colmenar).

Los primeros en establecer los contactos y formar parte de las reuniones entre la Fundación y el Colmenar fueron los responsables de hacer la tarea de promoción social del microcrédito. Se trataba de un grupo reducido de personas que tenía trabajadores de ambas organizaciones. Los pioneros en tomar el microcrédito fueron líderes comunitarios, quienes conformaron grupos basados en la confianza. Dado que la Mutual tenía estrecha relación con las organizaciones de base, lo primero que hizo fue promover el proyecto a través de éstas. Después, cuando la iniciativa empezó a expandirse y conocerse, se le fueron sumando los vecinos del barrio. La experiencia del trabajo conjunto, determinado por lógicas distintas de acción, dejó un aprendizaje valioso entre ambas organizaciones, que se traduce en la siguiente frase:

El mayor aprendizaje que se ha hecho con la Fundación es la construcción desde la diferencia. Creo que es uno de los mayores aprendizajes que ha hecho la Mutual y la Fundación también. El incorporar una cultura totalmente distinta" (Entrevista a informante clave de Mutual El Colmenar). 
REDES- Revista hispana para el análisis de redes sociales

Vol.9, \#5, Diciembre 2005.

http://revista-redes.rediris.es

La segunda etapa en el desarrollo de una red inter-organizacional implica la constitución de espacios de articulación (procesamiento de información, toma de decisiones). Desde el inicio comenzaron a tomarse determinaciones en conjunto, definiendo la zona de acción y el grupo que trabajaría en el Programa. Cuando la Fundación empezó a trabajar en la zona de Moreno centro, la Mutual los acompañó. Una vez que el Programa estuvo en marcha, las decisiones en conjunto pasaron a relacionarse exclusivamente con el ámbito operativo.

Yo creo que en este momento, la Fundación está teniendo esa repercusión. La Fundación salió a promocionar el proyecto sin la Mutual y recibió el reconocimiento de los vecinos" (Entrevista a informante clave de Mutual El Colmenar).

La información que se transmitía al interior de la alianza era sobre los resultados que iba generando el emprendimiento, sumado a aquélla que daban los trabajadores acerca de la capacitación que estaban recibiendo. La Mutual también empezó a promocionar el servicio a través de folletos acerca de todo lo relacionado con las acciones de la Fundación: qué hacían, dónde estaban, cuál era su lógica. Otra de las modalidades de comunicación, adoptada esta vez por una veintena de voceros de la Mutual, era ir casa por casa de los socios. Así se fue desarrollando una toma de compromiso de ambas partes.

En esta etapa, una vez instalado el Programa de Mejoramiento Habitacional de la Fundación, la misma comenzó a relacionarse más directamente con los vecinos. En este período de articulación, el evento más importante fue entonces la adopción del Programa por los vecinos.

... se reconoce y se instala dentro de la comunidad el crédito para el mejoramiento de la vivienda como una posibilidad" (Entrevista a informante clave de Mutual El Colmenar).

Luego algunos de los voceros de la Mutual se convirtieron en promotores del microcrédito de la Fundación, ya que se fue viendo la capacidad que tenía cada una de las personas para llevar adelante el proyecto; y dado que la Fundación tenía la idea de incorporar a la gente de la comunidad, la posibilidad finalmente se dio.

La tercera etapa en el desarrollo de esta relación está conformada por la constitución de espacios de gestión asociada (actividades diversas, proyectos o recursos comunes). La relación actual con la Fundación consiste en una alianza estratégica para trabajar en el mismo territorio, a través fundamentalmente del proyecto de la red de gas, y en la búsqueda de recursos y el acompañamiento en los proyectos que cada una de las organizaciones tiene. 
REDES- Revista hispana para el análisis de redes sociales

Vol.9, \#5, Diciembre 2005.

http://revista-redes.rediris.es

Es una relación de alianza de dos organizaciones que se están apoyando en el desarrollo de un territorio, son dos organizaciones que tienen cosas en común como la vocación de llegar a mucha gente, de trabajar para el barrio y los vecinos. Me parece que esa alianza es muy fuerte, porque no es fácil encontrar organizaciones con ese tipo de vocación" (Entrevista a informante clave de Mutual El Colmenar).

Además, entre la Mutual y la Fundación se fueron desarrollando acciones para enfrentar macro-problemas. En esta nueva etapa, la dificultad más acuciante para la Mutual es la permanencia del servicio de transporte. La Fundación se encuentra actualmente ayudando a la Mutual, buscando recursos para solucionarlos obstáculos. Puntualmente es el Director de la Fundación junto a un equipo de colaboradores, quienes más activamente están colaborando con El Colmenar, principalmente en la gestión de fondos, en temas como los cambios estructurales que son necesarios realizar, y asimismo ayudando a difundir el problema en la zona, para que se conozca la problemática.

...ahora con este problema la Fundación estuvo con el Colmenar, con este problema que ahora pasó. Son dos fundaciones que se conocen bien y trabajan bien, y trabajan en la misma zona" (Entrevista a Coordinadora del Programa).

5. 6 Los vínculos más formales del funcionamiento institucional: grupos y Fundación

Dado nuestro interés por los vínculos que existen entre los grupos que participan del microcrédito y la Fundación, consideraremos ahora los vínculos entre unos y otra, y su conexión por un conjunto de relaciones sociales. Por un lado, los grupos que participan del Programa de Mejoramiento Habitacional recurren a relaciones sociales más o menos inmediatas para tratar de solucionar los problemas que los afectan, basados en una relación entre los clientes y la Fundación por lo general consistente en una transferencia de fondos.

...pero yo sé que esa plata que estoy pagando es porque en un momento la Fundación me dio algo para que yo fuera a invertir en mi casa y pueda sentirme más satisfecha de haber hecho algo" (Grupo Focal).

Pero asimismo encontramos ciertos vínculos de apoyo entre ambos. 
REDES- Revista hispana para el análisis de redes sociales

Vol.9, \#5, Diciembre 2005.

http://revista-redes.rediris.es

\begin{abstract}
...es un proyecto entre las necesidades de la gente y... es como que sirvió para darnos una mano para toda la gente que no teníamos recursos. A lo mejor es como que [La Fundación] es más humanitaria, tiene más acceso a la gente y no es algo así frío como un crédito nomás y se siente diferente. Vos por ahí podés estar mal un mes y no aportar, y vas allá a hablar y te entienden. En cambio vos vas a un crédito y no; salís de tu casa y listo, chau. Es como que es mucho más humanitario (...) Aparte apoyo psicológico" (Entrevista a grupo El Parque).

...vínculo de comunicación siempre hay. Es más, hay personas que quizás nos toman como un referente para descargarse, eso también, en problemas individuales..." (Entrevista a Coordinadora del Programa).
\end{abstract}

A medida que se incrementan las conexiones de capital social al interior de una red, el acceso de una persona a los recursos y la información también aumenta. Las redes que se establecen entre los clientes y la Fundación representan maneras de intercambiar información y asimismo articular esfuerzos solidarios y facilitar procesos de aprendizaje entre la organización y los grupos. Igualmente estos intercambios no están exentos de conflictos, ya que en cierta medida la mutua dependencia y el contacto entre clientes y Fundación están asociados con el intercambio de recursos.

- ¿Qué pasó con el tío de tu señora?

- Mirá, quedó sin trabajo y después no se calentaba para pagar y nosotros queríamos seguir pagando pero hasta que después nos empezó a llegar cartas que como éramos un grupo teníamos que pagar nosotros, y bueno, nos hicieron en cuotas a nosotros, y a la otra vecina también y bueno, pagamos el monto que teníamos que pagar de ellos ¿no?, y bueno, fue así, y ellos no sé si terminaron de pagar" (Entrevista a grupo Macarena).

Igualmente hay que distinguir los distintos niveles que existen al interior de esta red que va desde la Sede Central hasta los grupos solidarios, pasando por la Subsede y las Promotoras. Más allá del establecimiento de vínculos estrechos al interior de los grupos solidarios, como ya desarrollamos, estos actores establecen diferentes relaciones fuera de su grupo de pertenencia para poder llevar a cabo el mejoramiento de su vivienda. Al interior de la red existen vínculos más o menos estrechos entre los diversos actores: 
REDES- Revista hispana para el análisis de redes sociales

Vol.9, \#5, Diciembre 2005.

http://revista-redes.rediris.es

Vínculos con las Promotoras: Si bien en una primera etapa la promoción se hacía en forma directa a través de los promotores de la Mutual, y en forma indirecta a través de las organizaciones comunitarias, actualmente la Fundación ha incorporado a los clientes como parte de la promoción vinculada a la tarea de reunir y completar la documentación para el armado del grupo. Los vínculos que establecen las Promotoras son principalmente con los grupos y con la Subsede, relacionado al trabajo cotidiano, la cercanía y al contacto frecuente entre sí.

...así yo hace siete años que estoy con la Fundación, y hoy estoy trabajando para la Fundación, somos clientes y estamos trabajando para ellos al mismo tiempo, y es algo muy lindo, que ellos... yo no me lo esperaba, lo que pasa es que uno a lo largo del tiempo fue aprendiendo lo que es el crédito y ellos dicen: 'Qué más que ustedes para traer a los clientes ya sabiendo cómo se maneja'..." (Entrevista a Promotoras).

Vínculos con la Subsede: El rol operativo de la Subsede en los distintos grupos solidarios es fundamentalmente el de facilitador de la comunicación, primero en la conformación de los grupos tratando que todos tengan la información adecuada, especialmente que la totalidad de los integrantes sepan del compromiso grupal de todos en relación con la responsabilidad de la garantía solidaria; y en segundo lugar, cuando hay dificultades en el grupo en relación al pago, se lo reúne en la Subsede o en su defecto en los hogares de los clientes, para que asuman la responsabilidad que tomaron inicialmente como grupo.

La Coordinadora del Programa se encuentra en una posición central en la red debido a su vinculación directa con la Sede Central, las Promotoras, los grupos solidarios y la Mutual El Colmenar. Ella junto a las Promotoras se autodenomina como "la cara visible de la Fundación" frente a los grupos solidarios. Las tareas que realiza la Coordinadora del Programa en la Fundación son variadas. Ella se encarga de capacitar y coordinar a las Promotoras, así como también de evaluar a los grupos, de la cobranza e incluso de las cuestiones relativas a la aparición de mora en los grupos, tareas que la acercan a la Sede Central.

Yo la verdad porque creo que tengo buen trato con los clientes. Vos fíjate que las dos cosas que yo hago son opuestas, o sea doy crédito pero también cobro si no lo pagás, ¿entendés? Yo creo, porque qué sé yo, porque tengo muy buena relación con, tengo feeling con los clientes, (...) uno se va haciendo relación, los vas conociendo" (Entrevista a Coordinadora del Programa).

Nosotros realmente tenemos relación con la Coordinadora, porque ella es la que nos atiende, ella es la que nos aconseja, ella es la que nos llama por teléfono; con ella sí estamos en contacto" (Entrevista a grupo Los Patacones). 
REDES- Revista hispana para el análisis de redes sociales

Vol.9,\#5, Diciembre 2005.

http://revista-redes.rediris.es

Vínculos con la Sede Central: Los vínculos que existen entre los grupos solidarios y la Sede Central son los más distantes entre sí. Las conexiones entre ambas partes consisten en una relación asimétrica de poder e influencia. A pesar de la asimetría la relación se mantiene debido a, podríamos decir, la necesidad de los miembros de los grupos por obtener el crédito para mejorar su vivienda. La relación entre las partes no es directa, se elevan informes de estudios o la comunicación se realiza indirectamente a través de la Subsede.

... las familias del barrio saben perfectamente bien qué es lo que ellos pueden hacer solos y que no, porque requieren de algún tipo de asistencia externa..." (Entrevista a Dir. Ejecutivo de FPVS).

...la Fundación no tiene mucha participación personal, esto no quiere decir que desapareció, porque somos quienes hacemos la gestión de los fondos, buscamos a otros socios, y toda la historia, capacitamos a esta gente, pero no vamos a ser el vínculo directo con los clientes" (Entrevista con informantes claves de la Fundación).

\section{A modo de Conclusión...}

El capital social constituye un recurso, que a su vez pone en funcionamiento otros recursos para mejorar las condiciones de vida de una población. Se presenta a continuación un esquema, que muestra los distintos tipos de capital social al interior de la red analizada en esta investigación: 
REDES- Revista hispana para el análisis de redes sociales

Vol.9, \#5, Diciembre 2005.

http://revista-redes.rediris.es

Figura 2

Tipos de capital social al interior de la red

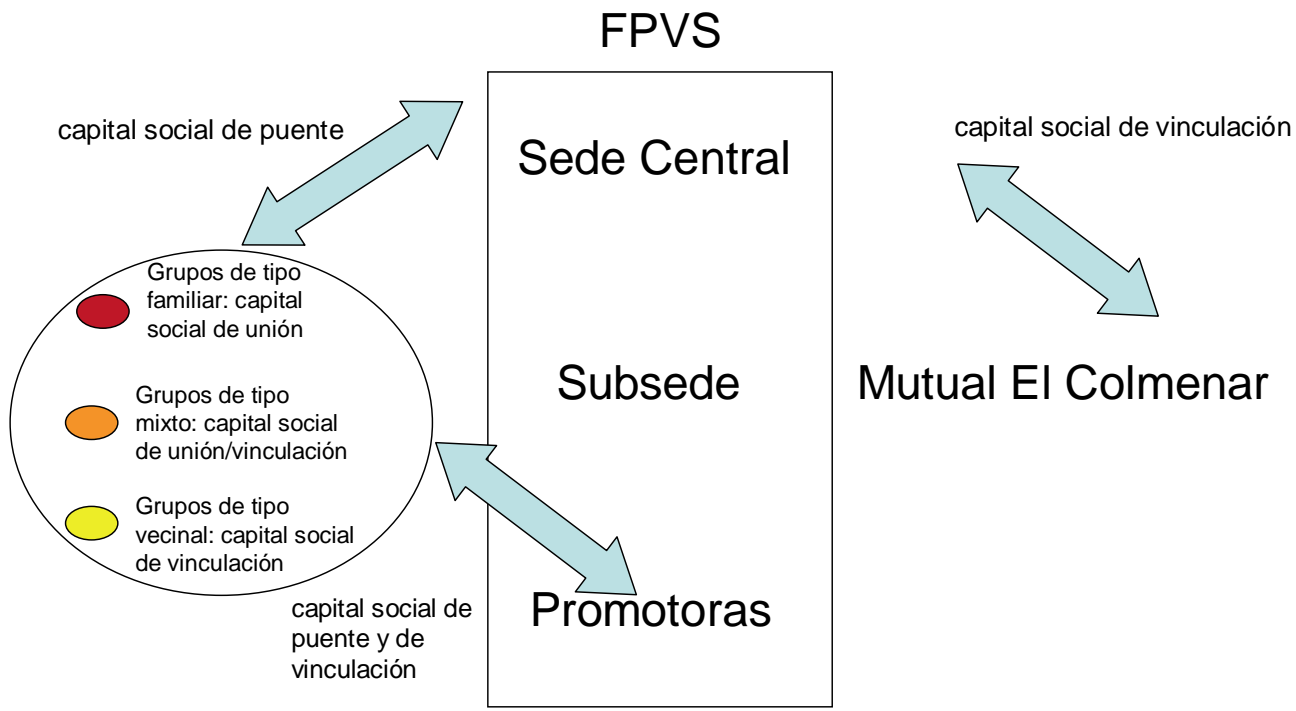

Los miembros de los grupos pueden mejorar su situación por gestionar socialmente los recursos y las necesidades, es decir, gracias a su alianza en micro-redes, sustentando su unidad en el capital social que generan. A partir del análisis del proceso de conformación de los grupos solidarios, encontramos que éstos se forman en parte gracias al conocimiento y relación previa entre los integrantes. En algunos casos eligen familiares, en otros vecinos o compañeros de trabajo, pero el elemento en común es que todos fueron recomendados por algún integrante del grupo y asimismo comparten el fin último de mejorar la vivienda. Planteamos como hipótesis que es necesaria la existencia previa de capital social entre algunos de los integrantes del grupo, para que el Programa de Mejoramiento Habitacional sea aplicable.

En los grupos de tipo familiar, cuando los vínculos se basan en puntos de coincidencia heredados o creados como resultado de compromisos para toda la vida y un contacto personal frecuente, existe entre los miembros una relación socialmente estrecha. Se trata de la generación de capital social de unión, basada en el afecto y la preocupación por el otro. El grado de implicación emocional asociado con la relación, o en otras palabras, la "carga emocional" entre los miembros del grupo familiar hace que las expectativas entre los miembros de este 
REDES- Revista hispana para el análisis de redes sociales

Vol.9, \#5, Diciembre 2005.

http://revista-redes.rediris.es

tipo de grupos sean más intensas, y por ello mismo la decepción frente a comportamientos oportunistas o al incumplimiento de lo estipulado repercute en este tipo de grupo en un grado mayor.

Entre los grupos de tipo vecinal encontramos un basamento de sentimientos moderadamente intensos de conexión, como la confianza, la buena voluntad recíproca y el compañerismo entre los miembros. Estos grupos constituyen una herramienta necesaria para la concreción del progreso de la vivienda o en un sentido más global, el mejoramiento de las condiciones de vida. En estos casos, la relación entre los integrantes parece estar directamente ligada a estos objetivos, aunque en determinados casos esta relación puede evolucionar hasta cimentarse en vínculos íntimos de confianza y cooperación.

Por ello, y por tratarse de puntos de coincidencia adquiridos entre los integrantes derivados del compromiso a mediano plazo que implica el pago de los créditos, podría afirmarse que entre ellos se genera un tipo de capital social diferente al anterior, el capital social de vinculación.

Si nos referimos a los grupos de tipo mixto, consideramos que así como la vinculación entre los miembros varía, cambia asimismo el tipo de capital social entre ellos. Básicamente en estos casos se trata de una combinación de vínculos de confianza, sentimientos de cooperación y compromiso que generan capital social de unión y vinculación, es decir que mientras entre algunos de los miembros existe el primer tipo de capital social, entre otros integrantes del mismo grupo existe otro, de tipo vincular.

Un aspecto interesante a destacar, y que requerirá de mayor estudio, es que el tipo de vínculos al interior de los grupos no influye necesariamente en el cumplimiento de la garantía solidaria y en la devolución del crédito del grupo hacia la Fundación. Observamos que grupos con vínculos diferentes han funcionado responsablemente. Dejamos planteado a modo de hipótesis que el tipo de vínculo al interior de los grupos (familiar o vecinal) no condiciona el cumplimiento de la garantía solidaria ni la devolución del crédito en tiempo y forma.

Los grupos, que a su interior constituyen redes densas, se valen asimismo de vínculos más débiles que pueden generar nuevos recursos y beneficios. En este artículo, si bien se ha tratado de avanzar con respecto al análisis de las redes sociales en un área geográfica específica, asimismo se ha prestado atención al estudio de las potencialidades, limitaciones, obstáculos y logros de las 
REDES- Revista hispana para el análisis de redes sociales

Vol.9,\#5, Diciembre 2005.

http://revista-redes.rediris.es

organizaciones destinadas a la vivienda, en el desarrollo de las prácticas de gestión que privilegian el desarrollo de responsabilidades colectivas.

Retomando aquí -al respecto de las relaciones inter-organizacionales- las formulaciones de Granovetter acerca de la importancia de los vínculos débiles, encontramos en nuestro caso que los grupos analizados logran disminuir la segmentación y el aislamiento propios de zonas de exclusión social, como son las áreas periféricas del partido de Moreno, donde residen, con características especialmente críticas en torno a la vivienda, los grupos pobres expulsados de las zonas de privilegio. El alcance de tales logros se debe en parte al establecimiento de redes densas al interior de los grupos, aunque asimismo éstos se valen de vínculos más débiles que pueden generar nuevos recursos y beneficios, generando mayores oportunidades de superar su situación. Puede decirse que FPVS refuerza las experiencias asociativas del tipo de pequeños grupos, factor que ayuda al fortalecimiento de vínculos de confianza, cooperación y contención entre los miembros.

La relación entre los grupos y la Fundación por lo general consiste en una relación de transferencia de fondos, de poca cercanía y basada en vínculos débiles. Se pudo así captar la capacidad de las influencias indirectas exteriores al círculo inmediato propio - de la familia, los amigos, los vecinos y los compañeros de trabajo más cercanos-, que sirven como un sistema de acceso a recursos diferentes. Las redes horizontales densas sostienen la cooperación dentro de cada grupo, pero las redes de compromiso cívico que logran atravesar los agujeros estructurales, alimentan una cooperación más amplia. Los pobres, al disponer de escasos recursos financieros, cuentan con su capacidad de generar capital social con personas muy diferentes a ellos mismos, mediante los "vínculos débiles". Siguiendo la tipología de capital social, podría decirse que entre grupos y Fundación existe capital social de puente. Dejamos planteado como hipótesis que así como los clientes utilizan los vínculos más formales y distantes en la red para la obtención de nuevos recursos, por su parte la Fundación convierte el capital social existente entre los vecinos de Cuartel $\vee$ en garantía solidaria. 
REDES- Revista hispana para el análisis de redes sociales

Vol.9,\#5, Diciembre 2005.

http://revista-redes.rediris.es

Puede señalarse que si bien los recursos provienen de la Sede Central, es en realidad la Subsede quien tiene el mayor grado de centralidad en la red considerada, en tanto posee vínculos con todos los actores de la red, se encuentra más cercana a todos ellos y está situada entre cada par de actores, constituyéndose en la articuladora del Programa en Cuartel V. Esto se debe a la estrategia de la dirección de la Fundación.

Existe un valioso capital en la Fundación, que está compuesto por su personal, especialmente aquellos que tienen contacto más frecuente con los clientes. En las Promotoras se acumula una invalorable experiencia y trato con las familias de la comunidad, sumado a su conocimiento institucional y a su alto grado de compromiso y participación hacia la Fundación y los grupos solidarios. Así, los vínculos que establecen las Promotoras, además de generar capital social de puente -por formar éstas parte de FPVS-, promueven también capital social de vinculación con los grupos solidarios, en tanto la relación con los clientes es de mayor frecuencia, conforman cada una un grupo solidario, viven en el mismo territorio que los clientes, hay una relación de cercanía, y tienen una situación similar en cuanto a recursos y carencias. Además las mismas quedan desvinculadas de las cuestiones de mora o dificultades en relación al pago, de las que se ocupa principalmente la Subsede. Por lo tanto, la Fundación a partir de la utilización de los propios clientes para la promoción, promueve el capital social entre ésta y los clientes, estrechando los vínculos que se suman a los “de aproximación” ya existentes.

Por último, debe destacarse la fuerte presencia de una organización comunitaria entre la población de Cuartel $\mathrm{V}$ estudiada, pero principalmente en las relaciones sociales que la misma establece con la Fundación. Las relaciones que establece FPVS con la Mutual El Colmenar implican un alto nivel de confianza entre las partes, así como una buena voluntad recíproca, apoyada en un trabajo conjunto de muchos años. Nos encontramos aquí frente al tipo de capital social de vinculación, que hace que ambos actores se comprometan el uno con el otro sin sacar ventaja de la confianza establecida. Los vínculos entre la Mutual y la Fundación son relativamente estrechos debido a que se trata de dos organizaciones que comparten objetivos y combinan métodos de trabajo que se complementan para desarrollar programas sociales en la comunidad en la que ambas operan. 
REDES- Revista hispana para el análisis de redes sociales

Vol.9, \#5, Diciembre 2005.

http://revista-redes.rediris.es

Al analizar el capital social a nivel comunitario en zonas de exclusión social, la consolidación de redes tiene un rol protagónico como forma de quebrar con la segmentación y el aislamiento presentes en la pobreza. Puede decirse que tanto los contactos y la unión de las personas pobres, como los vínculos establecidos con otros actores constituyen grandes oportunidades para los excluidos de superar su actual situación.

\section{Bibliografía}

Coleman, J.S. (1990). Foundations of Social Theory. Cambridge: Belknap Press of Harvard University Press.

Cheston, S. y Reed, L. (1999). “Medición de la transformación: Evaluación y mejora del impacto del microcrédito". Ponencia para la Reunión de Consejos de la Cumbre de Microcrédito. Adbuja, Costa de Marfil: www. microcreditsummit. org/pdfs/impactpapersp.pdf

Forni, P. (2002a). "Las redes inter-organizacionales y sus implicancias en el desarrollo de las organizaciones comunitarias de los pobres y excluidos. Estudios de caso en el Gran Buenos Aires (1995-2000)". Ponencia presentada en el Primer Congreso Nacional de Políticas Sociales, Universidad Nacional de Quilmes. En: http://www. salvador.edu.ar/csoc/idicso/docs/aongpppf2.pdf

Forni, P. (2002b). "La búsqueda de nuevas formas de organización popular: Del Consejo de la Comunidad a la Mutual El Colmenar". En Forni, F. (comp.), De la exclusión a la organización. Hacia la exclusión de los pobres en los nuevos barrios del conurbano bonaerense. Buenos Aires: Ediciones Ciccus.

Forni, P., Siles, M. y Barreiro, L. (2004). “¿Qué es el Capital Social y cómo Analizarlo en contextos de Exclusión?" en: www.jsri.msu.edu.

Granovetter, M. (1973). "The Strength of Weak Ties", en: http://www.personal.si.umich.edu/ rfrost/courses/SI110/readings/In_Out_and_Be yond/Granovetter.pdf.

Hanneman, R. A. (2000). Introducción a los métodos de análisis de redes sociales, Departamento de Sociología de la Universidad de California Riverside, en: http://revistaredes. rediris. es/webredes/textos/Introduc.pdf.

Portes, A. (1999). "Capital Social: Sus orígenes y aplicaciones en la sociología moderna" en Carpio, J. y Novacovsky, I. (comp.), De Igual a Igual. El desafío del Estado ante los nuevos problemas sociales. Buenos Aires: Fondo de Cultura Económica, pp 243-267.

Putnam, R. (1993). Making Democracy Work. New Jersey: Princenton University Press.

Putnam, R. (2000). Bowling Alone: The Collapse and the Revival of American Community. New York: Simon and Schuster.

Robison, L., Siles, M. y Schmid, A. (2003). “El capital social y la reducción de la pobreza: hacia un paradigma maduro" en Atria, R. y Siles, M. (comp.) Capital social y reducción de la pobreza en América Latina y el Caribe: En busca de un nuevo paradigma, CEPAL - M.S.U., Santiago de Chile. En: http://www.eclac.cl/cgibin/getProd.asp?xml=/prensa/noticias/comunicados/3/7903 /P7903.xml\&xsl=/prensa/tpl/p6f.xsl\#top. 